\title{
Evaluation of the influence of calcium chloride on the behavior of phases of nanosystems applied in the larvicidal control of Aedes aegypti
}

Avaliação da influência do cloreto de cálcio no comportamento de fases de nanossistemas aplicados no controle larvicida do Aedes Aegypti

Evaluación de la influencia del cloruro de calcio en el comportamiento de fases de nanosistemas aplicados en el control larvicida de Aedes Aegypti

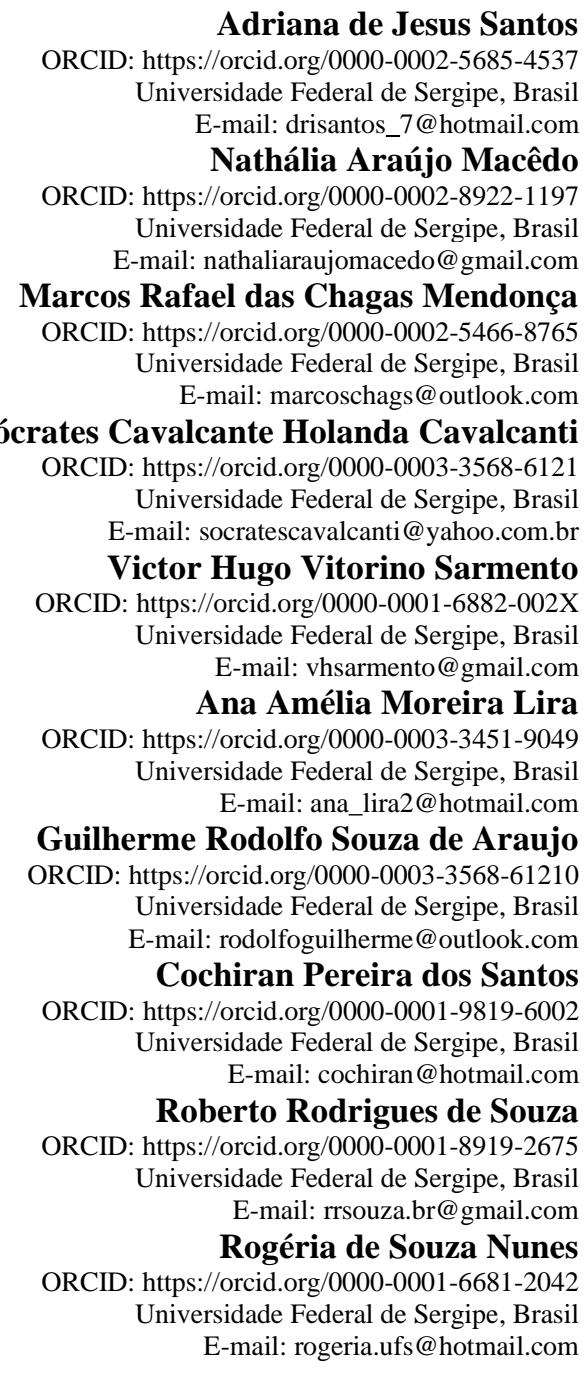

\begin{abstract}
Systems stabilized by surfactants in order to incorporate different substances at their interfaces, such as hydrophilic polymers and active compounds, are systems capable of establishing vector control of Aedes aegypti. The system was obtained through the surface tension of PPG-5-CETETH-20/calcium chloride dispersion at concentrations of $0.2 \%$, $0.4 \%, 0.8 \%, 1 \%$ and $2 \%$, determining the CMC of each sample. Then, a binary study was performed and the system structures were evaluated by Polarized Light Microscopy (PLM) and rheological analysis. Biological analysis was performed to assess the mean lethal concentration $\left(\mathrm{LC}_{50}\right)$ against Aedes aegypti larvae and toxicity to non-target organisms in Artemia salina. In this sense, the objective of this work was to evaluate the influence of calcium chloride
\end{abstract}


on the behavior of phases and on the biological activity of formulations based on the self-aggregation of surfactants, an alternative larval insecticide to be used as a replacement for larval insecticides already on the market.

Keywords: Surfactants; Stabilized systems; Larvicidal control; Aedes aegypti; Artemia salina.

\section{Resumo}

Sistemas estabilizados por surfactantes podem incorporar diferentes substâncias em suas interfaces, como polímeros hidrofílicos e compostos ativos, e são sistemas capazes de estabelecer o controle vetorial do Aedes aegypti. O sistema foi obtido através da tensão superficial da dispersão de PPG-5-CETETH-20/cloreto de cálcio nas concentrações de 0,2\%, 0,4\%, 0,8\%, $1 \%$ e 2\%, determinando a CMC de cada amostra. Em seguida, foi realizado um estudo binário e as estruturas do sistema foram avaliadas por Microscopia de Luz Polarizada (MLP) e análise reológica. A análise biológica foi realizada para avaliar a concentração letal média $\left(\mathrm{CL}_{50}\right)$ contra larvas de Aedes aegypti e toxicidade para organismos não-alvo em Artemia salina. Nesse sentido, o objetivo deste trabalho foi avaliar a influência do cloreto de cálcio no comportamento das fases e na atividade biológica de formulações baseadas na autoagregação de tensoativos, um inseticida larval alternativo a ser utilizado como substituto de inseticidas já existentes no mercado.

Palavras-chave: Tensoativos; Sistemas estabilizados; Controle larvicida; Aedes aegypti; Artemia salina.

\section{Resumen}

Los sistemas estabilizados con surfactantes pueden incorporar diferentes sustancias en sus interfaces, como polímeros hidrofílicos y compuestos activos, y son sistemas capaces de establecer el control de vectores de Aedes aegypti. El sistema se obtuvo mediante la tensión superficial de la dispersión de PPG-5-CETETH-20/cloruro de calcio en concentraciones de $0,2 \%, 0,4 \%, 0,8 \%, 1 \%$ y $2 \%$, determinando la CMC de cada muestra. Luego, se realizó un estudio binario y se evaluaron las estructuras del sistema mediante Microscopía de Luz Polarizada (MLP) y análisis reológico. Se realizó un análisis biológico para evaluar la concentración letal media (LC50) contra larvas de Aedes aegypti y la toxicidad para organismos no objetivo en Artemia salina. En este sentido, el objetivo de este trabajo fue evaluar la influencia del cloruro de calcio en el comportamiento de las fases y en la actividad biológica de formulaciones basadas en la autoagregación de tensioactivos, una alternativa insecticida larval para ser utilizada como sustituto de insecticidas que ya están en el mercado.

Palabras clave: Tensioactivos; Sistemas estabilizados; Control de larvicidas; Aedes aegypti; Artemia salina.

\section{Introduction}

Brazil has faced a major public health challenge due to outbreaks involving several arboviruses transmitted by Ae. aegypti, including dengue, Zika virus, wild yellow fever and Chikungunya (Santos et al., 2020). These arboviruses present a constant threat to human health, with the highest number of notifications being found in tropical and subtropical areas (Souza et al., 2020; Santana et al., 2021), where environmental impacts and climatic conditions of temperature and humidity allow the maintenance of the viral cycle (Fujiwara et al., 2017). Due to the high number of notifications, the Brazilian Ministry of Health has coordinated with the state and municipal health secretariats to carry out task forces in order to control the emergence of new cases (Maia et al., 2019).

In this scenario, the control of Ae. aegypti is presented as the main preventive measure to reduce the spread of these related arboviruses (Souza et al., 2020). For vector control, basically, three methodologies are used: physical or mechanical control, biological control and chemical control (Maia et al., 2019).

Chemical control is still one of the main mechanisms used by the World Health Organization (WHO). Among the various larvicidal agents available on the market, only three classes are approved by the WHO for use against Ae. aegypti, which are the organochlorines, carbamates and pyrethroids (Aguiar, 2017; Maia et al., 2019). However, the continuous use of these insecticides over the years has shown worrying results regarding the selection of resistant individuals (Corte et al., 2018; Fonseca et al., 2019; Martins et al., 2021).

The use of these insecticides has also caused damage to humans and the environment, thus, several technological innovations of vector control have been developed as alternatives to the control of Ae. aegypti using different mechanisms of action, such as social measures, selective monitoring of the infestation, insecticide dispersion, new chemical and biological control agents and molecular procedures for mosquito population control, including combinations of techniques (Zara et al., 2016; Alvarez Costa, 2018). 
On the other hand, there are studies that report the synthesis of new organic compounds in order to evaluate the activity against Ae. aegypti seeking to develop strategies to control its proliferation (Nunes et al., 2018). However, there are some limitations in the direct use, such as insolubility in water, and the main limitation of the direct use of compounds in aqueous medium is the low solubility in this medium.

Thus, a system was developed using a non-ionic surfactant, completely soluble in water and ethanol. Its composition provides multiple functionality: emollient, solubilizer, plasticizer and wetting agent, favoring the dispersion of the active compound ( $N$-tosylindole). This system is structured and presents itself as a promising system for releasing active substances.

The addition of calcium chloride (electrolyte) in the aqueous phase causes a change in the solvent property of water, alters the solubility of the surfactant in the medium and, as a consequence, promotes a decrease in the critical micellar concentration (CMC). This decrease generates aggregates with different structures when the surfactant is in high concentrations, improving the biological response of the carrier substance (Galindo-Alvarez et al., 2011; Grządka et al., 2017).

\section{Methodology}

\subsection{Surface tension and determination of Critical Micellar Concentration}

The determination of Critical Micellar Concentration (CMC) was analyzed with an Attension Tensiometer model Sigma 700, using the Wilhelmy plate method. For the experiment, Milli-Q ${ }^{\circledR}$ water was used as a standard, and its surface tension was previously measured $(\gamma=72.00 \mathrm{mN} / \mathrm{m})$. Then, an initial aqueous solution of $0.5 \mathrm{~g} / \mathrm{l}$ was prepared for the surfactant PPG-5-CETETH-20 and for the mixture PPG-5-CETETH-20/calcium chloride, and from these, dilutions were carried out in water at concentrations of $0.2 \%, 0.4 \%, 0.8 \%$ and $1 \%$ and subjected to analysis in the equipment (Froelich et al., 2017). The experiment was performed in triplicate for each dilution point. Surface tension values $(\mathrm{mN} / \mathrm{m})$ were determined as a function of surfactant concentrations $(\mathrm{g} / \mathrm{l})$.

\subsection{Phase behavior of PPG-5-CETETH-20 surfactant in water and PPG-5-CETETH-20/calcium chloride dispersion at $2 \%$}

The lyotropic phase behavior of the surfactant PPG-5-CETETH-20 and PPG-5-CETETH-20/AO 2:1 was verified. The phase behavior was also evaluated for mixtures of these components with increasing concentrations of water in an aqueous solution of Alginate and Calcium Chloride. Each system was mixed with water in proportions 1:9, 2:8, 3:7, 4:6, 5:5, 6:4, 7:3, 8:2 and 9:1. After homogenization, the systems were left to rest for a period of five days for stabilization, then the phases formed were observed and identified by Polarized Light Microscopy (PLM).

\subsection{Development of the system through the ternary phase diagram with PPG-5- CETETH-20/soybean oil/calcium chloride dispersion}

The surfactant (PPG-5-CETETH-20) was combined in different ratios and mixed under magnetic stirring to the oil phase. They were added and homogenized for 30 minutes at room temperature. After complete homogenization, the aqueous phase was added to the mixtures still under stirring. To obtain the formulation, the non-ionic surfactant Procetyl AWS (PPG-5CETETH-20), commercial soybean oil as the oil phase, calcium chloride dispersion as the aqueous phase and $N$-tosylindole as the active compound were used.

A mixture of surfactant (74\%) and 6\% oil phase was prepared and subjected to magnetic stirring for 30 minutes. Then, after complete homogenization, $20 \%$ of the $2 \%$ calcium chloride dispersion (aqueous phase) was added dropwise, still under magnetic stirring, the whole process being carried out at room temperature. After mixing the surfactant and the oil phase under the same conditions described in the preparation of the inert formulation, $0.01 \%$ of the active compound $\mathrm{N}$-tosylindole was 
incorporated and subjected to magnetic stirring for 30 minutes. After homogenization, $20 \%$ of the $2 \%$ calcium chloride dispersion (aqueous phase) was added. Formulations FC1A, FC2A and FC3A (inert) and FC1B, FC2B and FC3B (active compound) were obtained.

After each addition, the visual appearance of each sample was recorded and the phase changes were visually identified and classified as isotropic liquids (IL), transparent high viscosity systems (THVS), opaque systems and phase separation. Upon identifying the phase shift, the data were plotted using the Sigma Plot v. 11. To confirm the nature of the phases of the systems obtained, the technique of polarized light microscopy (PLM) was used.

\subsection{Characterization of systems by Polarized Light Microscopy (PLM)}

The identification of the optical properties of the systems obtained from the ternary phase diagram was performed by polarized light microscopy, using an Olympus BX-51 microscope equipped with a LC Color Evolution digital camera (PLA662) and Image Analyzer Software (PixeLINK). For measurements, the samples were applied to a glass slide, covered by a coverslip and analyzed. The images were obtained at a 20x magnification at room temperature, after a minimum time of five days for the equilibrium of the systems (Ferreira et al., 2015; Zhang \& Wang, 2019).

\subsection{Selection of systems for characterization}

The choice of systems was based on the lyotropic and phase precursor behavior. Low viscosity systems that increase their rigidity by increasing the aqueous phase were selected. To the formulations selected by PPG-5-CETETH-20/soybean oil/calcium chloride dispersion, $10 \mathrm{mg} / \mathrm{l}$ of the compound was incorporated and named as FC1B, FC2B and FC3B. What makes them different is the composition of the aqueous phase, which varies from 10 to $30 \%$. After the incorporation of the compound, the formulations were homogenized at room temperature and their visual appearance was observed for physicalchemical characterization.

\subsection{Rheological analysis}

The flow test was performed by varying the shear velocity from 0 to $200 \mathrm{~s}^{-1}$. The rheometer used was the controlled tension, model MCR-302 (Anton Paar), with cone/plate geometry, with a stainless steel cone with a diameter of $50 \mathrm{~mm}$ and an angle of 1 degree, with a spacing of $96 \mu \mathrm{m}$ from the cone to the plate. The formulation was tested at a controlled temperature of $(25.0 \pm 0.2){ }^{\circ} \mathrm{C}$. The sample was carefully applied to the bottom plate, ensuring minimal shear and allowing a 1 minute rest time before each determination. The analysis lasted 4 minutes. The data were fitted with the Power Law model through the OriginPro software (Ferreira et al., 2015).

\subsection{Biological assays}

To determine the larvicidal activity of the formulation, aqueous solutions of $100 \mathrm{ml}$ were prepared, ranging from 0.02 to $5.00 \mathrm{ppm}$, where 20 Rockefeller larvae of Aedes aegypti L3/L4 stage were submitted. Assays were performed in triplicate. After $24 \mathrm{~h}$, the number of dead larvae was verified, and the larva that showed no movement was considered dead. The assay was performed in triplicate and the inert formulation was used as a control, the conditions used were the same as previously established (Santos et al., 2020). Statistical analysis was performed to find the lethal concentration $50 \%\left(\mathrm{LC}_{50}\right)$. Data were subjected to PROBIT analysis according to Finney (1971). 


\subsection{Artemia salina toxicity test}

It was performed by adapting the methodology of Meyer et al. (1982), preparing a solution with sea salt at a concentration of $35 \mathrm{~g} / \mathrm{l}$. Initially, $100 \mathrm{mg}$ of cysts were incubated in $1000 \mathrm{ml}$ of standard artificial sea water $(3,5 \%)$ under lighting and aeration. After $18 \mathrm{~h}$ to $24 \mathrm{~h}$ of incubation, the nauplii (phases II to III) were transferred to a beaker containing 200 $\mathrm{ml}$ of artificial sea water, with lighting and aeration for $48 \mathrm{~h}$. Ten larvae of Artemia salina were transferred to $50 \mathrm{ml}$ disposable cups containing artificial sea water solution (Santos et al., 2020). The components were tested at concentrations from $5 \mathrm{ppm}$ to $1000 \mathrm{ppm}$. The nauplii were exposed to a test solution for $24 \mathrm{~h}$, recording total mortality.

\section{Results and Discussion}

\subsection{Determination of Critical Micellar Concentration (CMC)}

The CMC values represented in Figure 1, obtained for the pure PPG-5-CETETH-20 surfactant was $0.198 \mathrm{~g} / \mathrm{l}$, a value similar to that found by Vogel (2011).

The geometric position of the surfactant at the interface can be an influencing factor to be considered, in terms of its effects on the curvature and fluidity of the interface (Ho et al., 1996). According to Damasceno et al. (2011), the addition of a co-surfactant is able to reduce the free energy at the interface and the stress, through penetration into the surfactant film and, therefore, create a disordered film due to an empty space between the surfactant molecules.

Figure 1: Surface tension of PPG-5-CETETH-20 as a function of concentration. a) surface tension of pure PPG-5-CETETH-20 surfactant; b) PPG-5-CETETH-20/calcium chloride at 0,2\%; c) PPG-5-CETETH-20/calcium chloride at 0,4\%; d) PPG-5CETETH-20/calcium chloride at 0,8\%; e) PPG-5-CETETH-20/calcium chloride at 1\%; f) PPG-5-CETETH-20/calcium chloride at $2 \%$.

a) PPG-5-CETETH-20

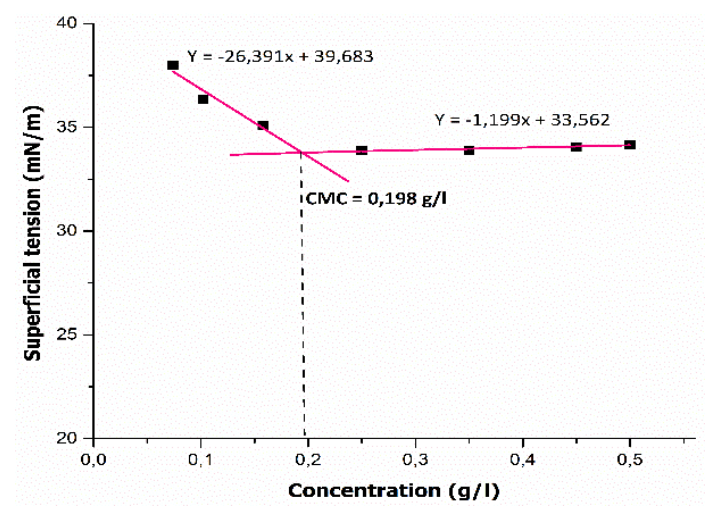

c) PPG-5-CETETH-20/calcium chloride at $0,4 \%$

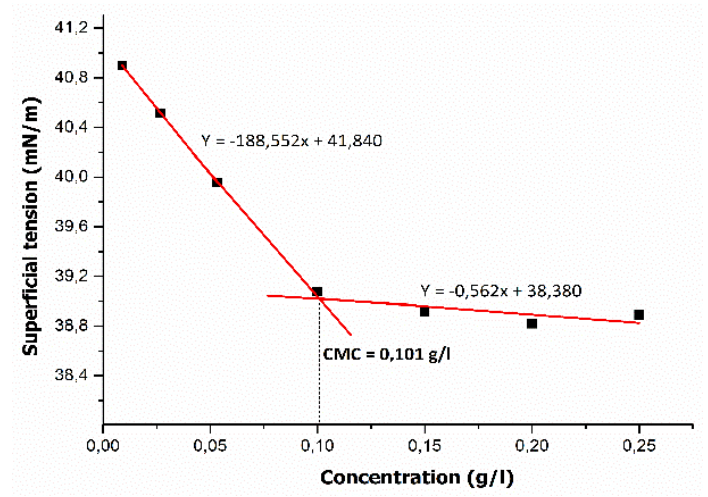

b) PPG-5-CETETH-20/calcium chloride at $0,2 \%$

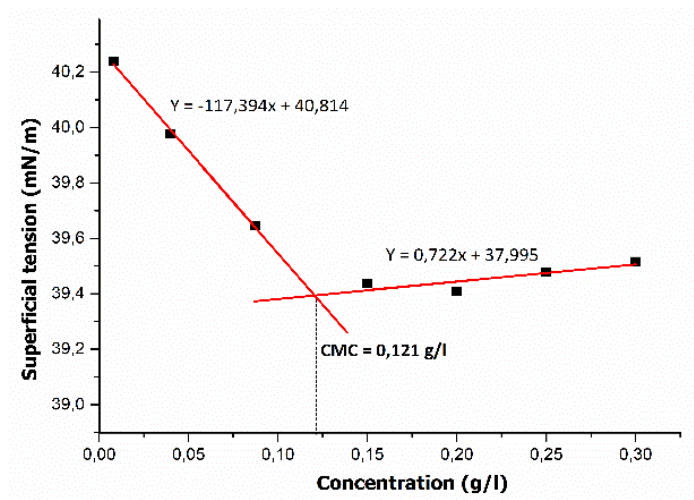

d) PPG-5-CETETH-20/calcium chloride at 0,8\%

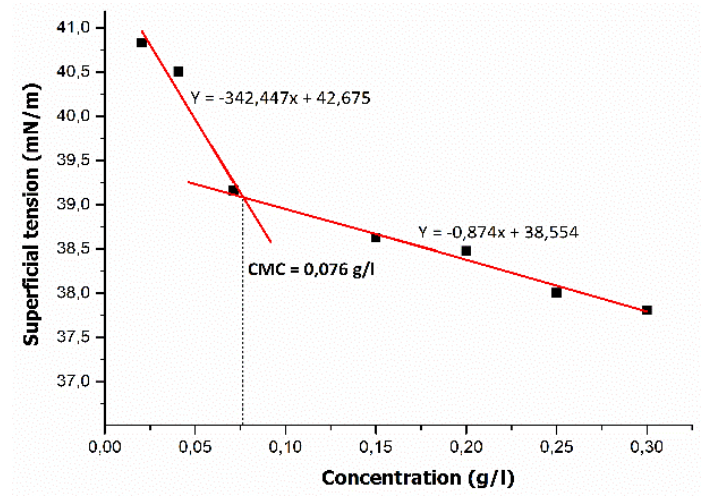


e) PPG-5-CETETH-20/calcium chloride at $1 \%$

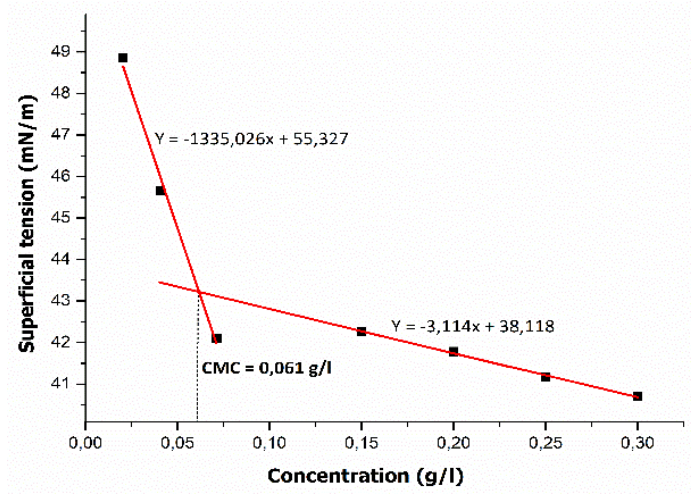

f) PPG-5-CETETH-20/calcium chloride at $2 \%$

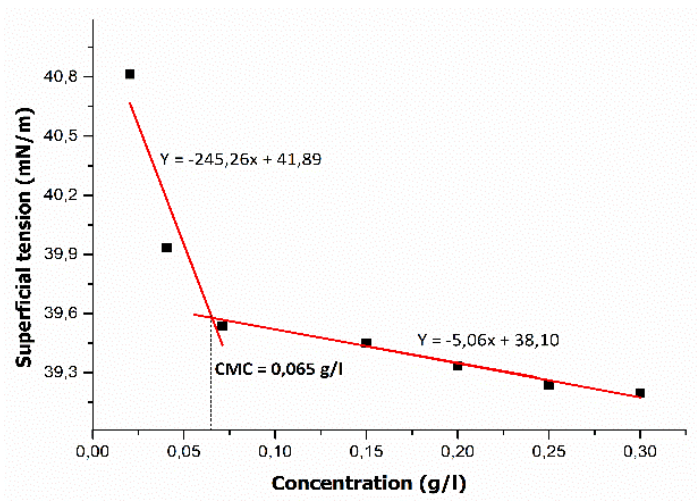

Source: Authors (2019).

Calcium chloride is a salt formed from calcium and chlorine, which is soluble in water. In the presence of a non-ionic surfactant in an aqueous medium, such as PPG-5-CETETH-20, it reduces its solubility due to the "salting out" phenomenon arising from the addition of ions to the medium by calcium chloride (Riccardi et al., 2019). Figure 1 shows the results of the addition of calcium chloride at concentrations of $0.2 \%, 0.4 \%, 0.8 \%, 1 \%$ and $2 \%$, and the addition of calcium chloride reduced the CMC of the PPG-5-CETETH-20 (Table 1), however, it can be seen that the decrease was proportional to the increase in concentration.

This influence is justified by the absence of ionic charge in the structure of the surfactant, and it is possible to observe the influence on the formation of aggregates by altering the solubility of the surfactant in the aqueous medium. Electrolytes have high solubility in the medium, which causes desolvation of the polar region of the non-ionic surfactant, generally resulting in a decrease in CMC (Huang et al., 2015; Salvia et al., 2016).

\subsection{Phase behavior of PPG-5-CETETH-20 surfactant in water and PPG-5-CETETH-20/calcium chloride dispersion at} $2 \%$

Through this study, it was possible to understand the behavior of the surfactant molecules when the proportion of aqueous phase is varied, as well as the proportion of the surfactant. The systems obtained are isotropic (micellar and/or micro emulsified systems), anisotropic (lamellar, hexagonal and cubic phase liquid crystals) and emulsified systems.

Figure 2 shows an illustrative schematic of the binary phase diagram obtained from PPG-5-CETETH-20/water and contact with up to $20 \%$ water in optically clear, liquid and isotropic systems classified as SLI. Above $20 \%$ of water, the systems turned into the hexagonal phase, verified by the observation of striations in the PLM, it has the appearance of a gel, transparent and has high viscosity. The hexagonal phase was maintained with the addition of up to $40 \%$ of water, above this amount, the system changed to the cubic phase. With the addition of water in concentrations above $80 \%$, the systems returned to SLI. 
Figure 2: Illustrative scheme of binary phases resulting from PPG-5-CETETH-20/water and PPG-5-CETETH-20/calcium chloride at $2 \%$ dispersion mixtures, in addition to representative images obtained by polarized light microscopy taken at $20 \mathrm{x}$.
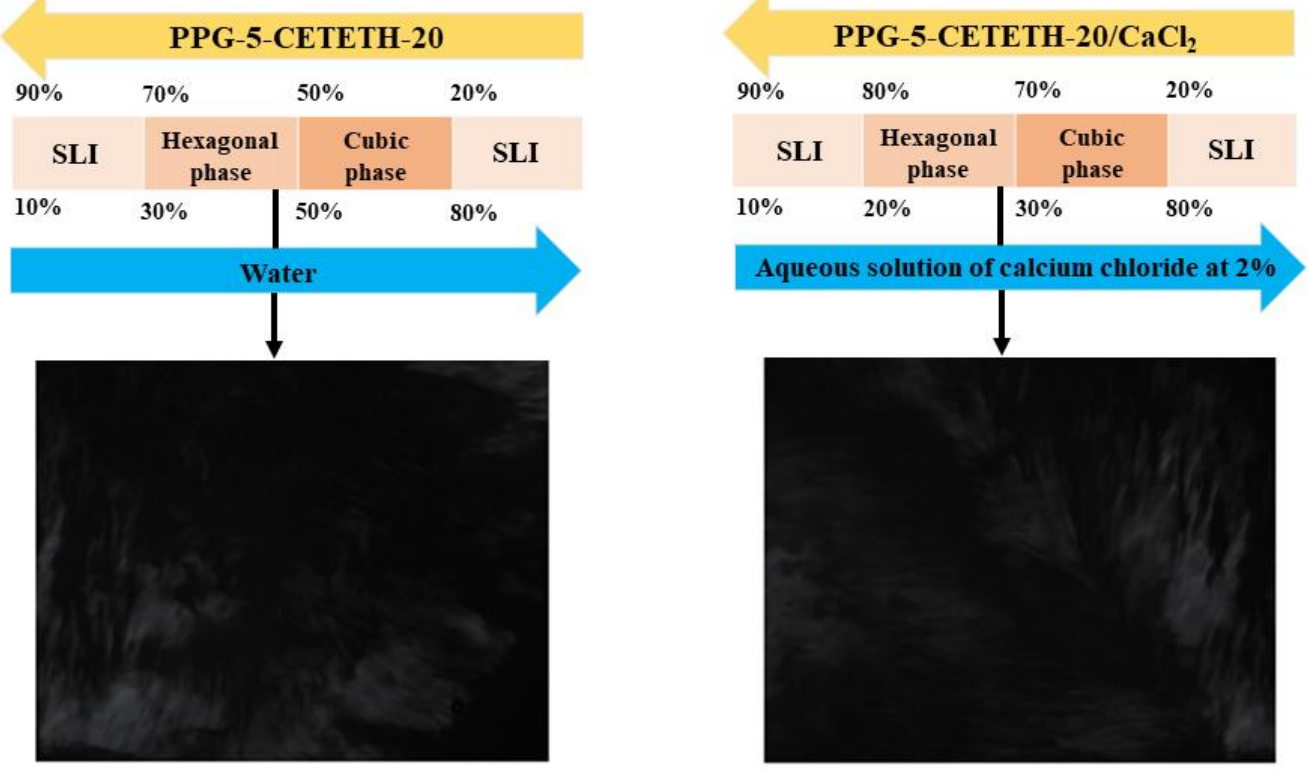

Source: Authors (2019).

The mixture of surfactant PPG-5-CETETH-20/calcium chloride at $2 \%$ promoted the formation of increasingly organized structures, with the dispersion of the aqueous solution there was a transition from SLI to the hexagonal phase, followed by the cubic phase, until that with a higher concentration of dispersed water, the system returns to being an SLI. In non-ionic surfactants with a single carbon chain, such as PPG-5-CETETH-20, the addition of water causes the agglomeration of the surfactant molecules, whose polar heads are turned towards the internal aqueous medium, in order to obtain a minimum state. of free energy, thus forming reverse micelles. The increase in water above $20 \%$ promotes the packing of these hexagonal phase structures, resulting in a more ordered phase, such as the cubic phase, whose interface has curvature around both the hydrophobic chain and the polar head of the surfactant.

The dispersion of calcium chloride at $2 \%$ as an aqueous phase in the presence of a non-ionic surfactant in an aqueous medium, such as PPG-5-CETETH-20, reduces the solubility of the polar part of the surfactant, providing self-organization. In the addition of $30 \%$ of aqueous phase, it was possible to obtain more structured systems, with the addition of 40 and $50 \%$, the system passes to the cubic phase and returns to SLI with $60 \%$ of aqueous phase.

\subsection{Polarized Light Microscopy (PLM)}

It is possible to observe that all samples presented a dark field when observed under the microscope (Figure 3). Isotropic systems, such as microemulsions, have a single refractive index, and their optical properties are independent of direction. Thus, they are not birefringent and generate a dark field when subjected to polarized light (Hyde, 2001; Ferreira et al., 2015).

In the photomicrographs of the FC2A and FC2B samples, it was possible to visualize structures similar to striations, characteristic of a hexagonal phase. Anisotropic systems have distinct crystallographic axes and interact with light in a way that is dependent on the orientation of the crystal lattice in relation to incident light, presenting birefringence (Abramowitz; Davidson, 2012).

The addition of aqueous phase by $30 \%$ (FC3A and FC3B) promoted a different organization between the arrays, being revealed through the anisotropy of the samples, visualizing characteristic structures of the cubic phase liquid crystalline array. 
Figure 1: Micrographs taken at 20x of samples FC1A, FC1B, FC2A, FC2B, FC3A and FC3B.
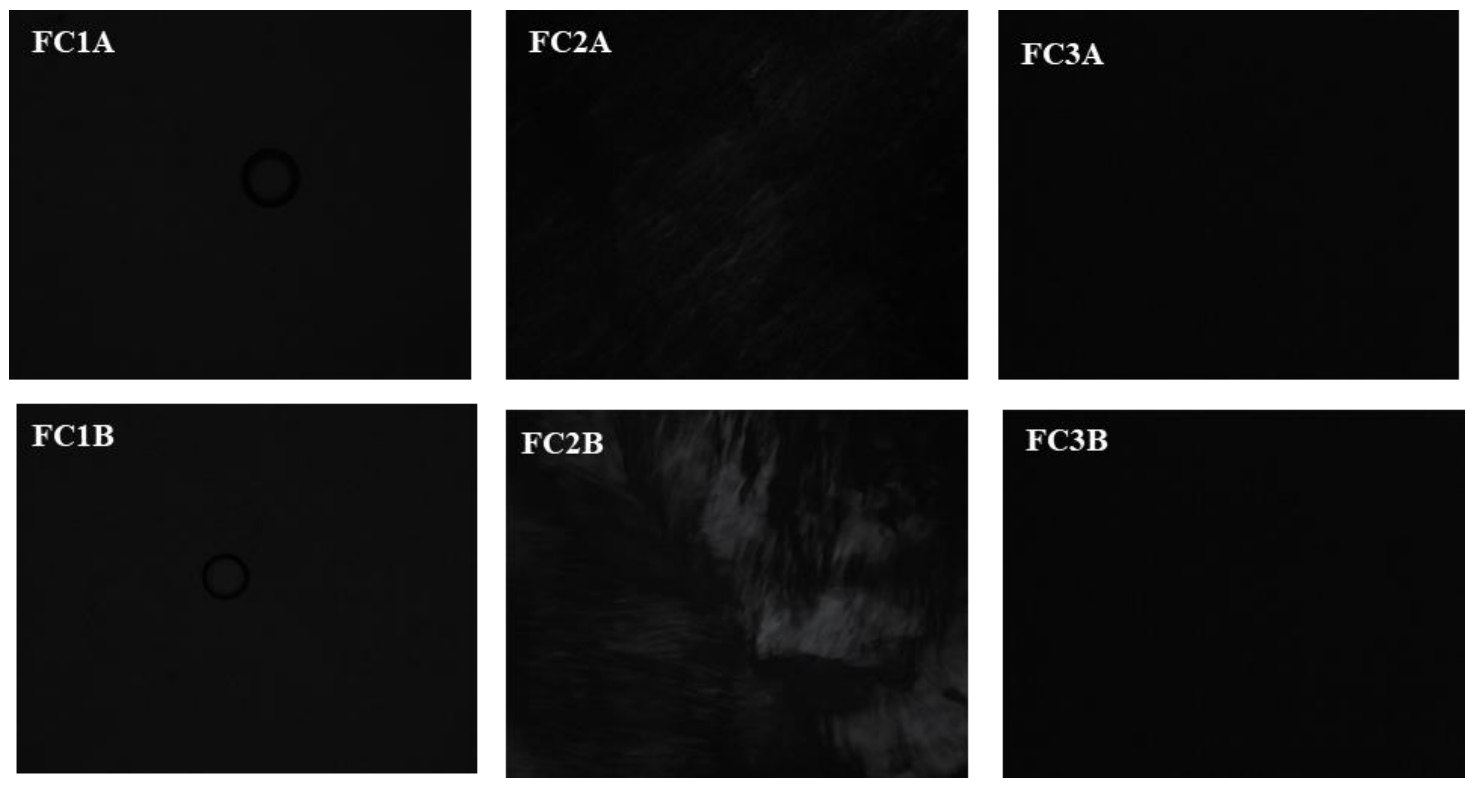

Source: Authors (2019).

\subsection{Rheological Analysis}

In Figure 4 it is possible to observe the rheological parameters of the samples FC1A, FC1B, FC2A and FC2B, in which all presented Newtonian behavior, presenting values of $\mathrm{R}^{2}>0.98$, indicating a good correlation between the experimental and theoretical data, with $n$ equal to or close to 1 , which is expected for microemulsion systems and ME-CL phase transitions (Santana et al., 2012). These systems exhibit this type of behavior due to the small droplet size and low interaction between them (Polizelli et al., 2006).

Figure 4: Rheograms of samples FC1A, FC1B, FC2A and FC2B with ascending curves.

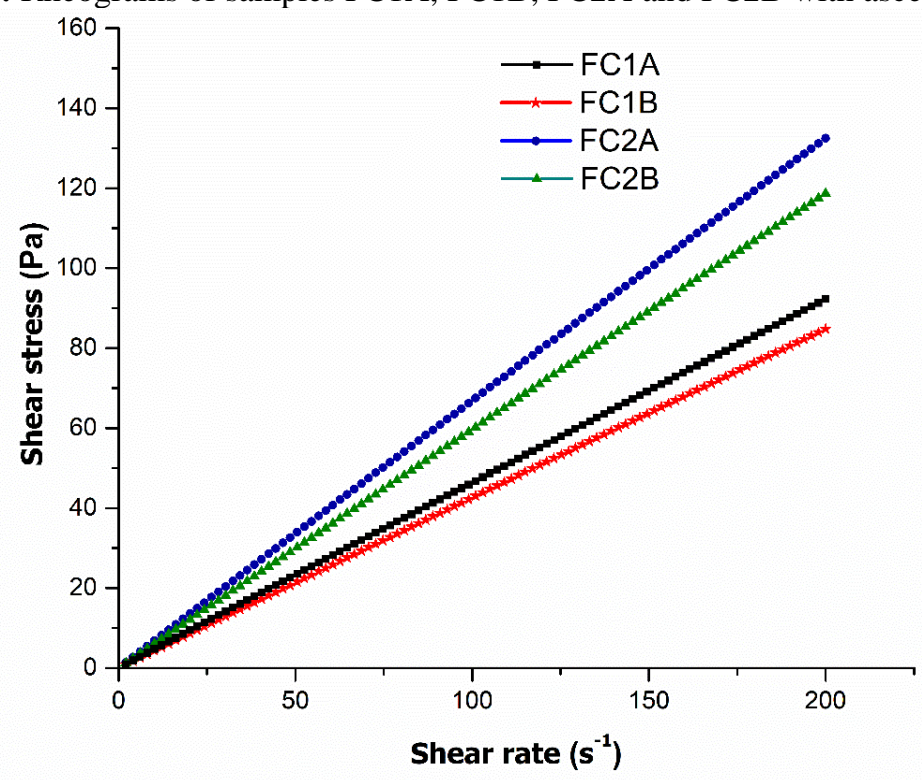

Source: Authors (2019). 
Likewise, Polizelli et al. (2006) in their study also obtained Newtonian behavior for microemulsions containing soybean oil. Rheological studies with microemulsions indicate that these systems commonly exhibit Newtonian behavior and their viscosity depends on the structure of the system.

To determine the behavior of the liquid crystalline phases, oscillatory analysis was performed for the sample FC3A and FC3B (Figure 5). The rheological characterizations were determined from the storage or elastic modulus (G') and loss modulus (G”) as a function of frequency. It was possible to observe that the samples present values of G'> G' independent of the frequency, indicating that the elastic properties overlap the viscous ones. High values for the storage modulus reflect in an elastic, highly structured sample with strong interactions between molecules (Yariv et al., 2010; Carvalho et al., 2013).

Figure 5: Elastic modulus $\left(G^{\prime}\right)$ and loss (G”) as a function of the frequency of samples FC1A, FC1B, FC2A and FC2B.

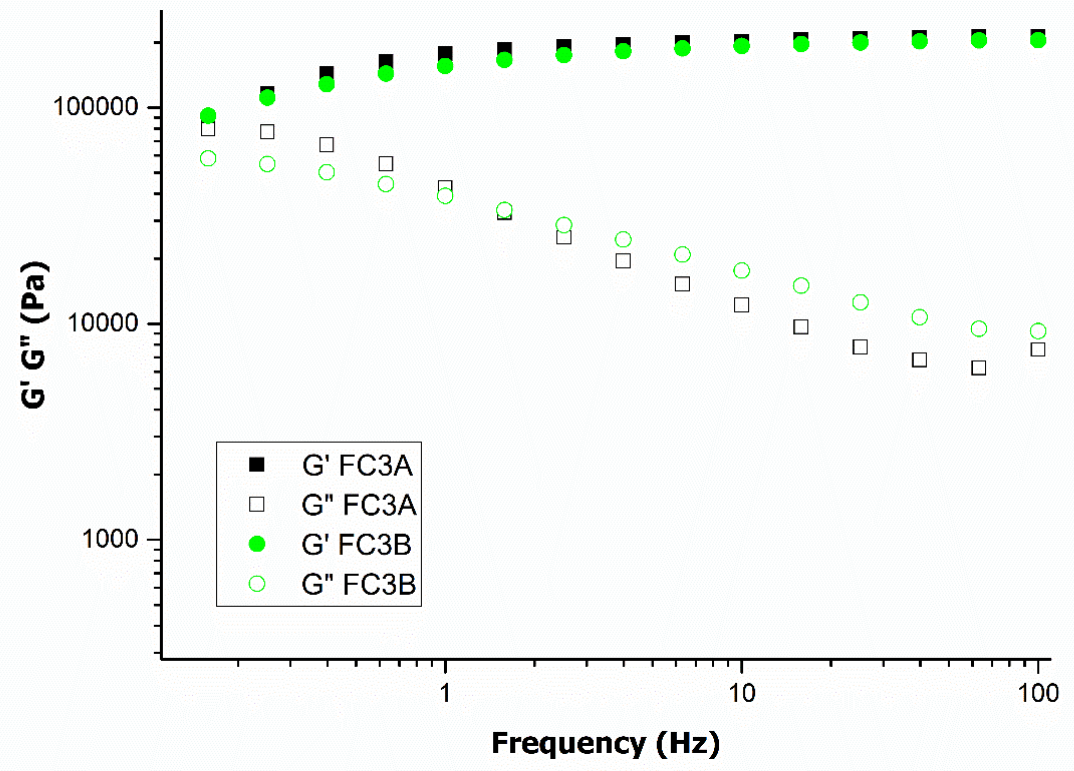

Source: Authors (2019).

According to Ling et al. (2014), the increase in the storage modulus G' is attributed to the ability of the surfactant molecules to adsorb at the interfaces, while the loss modulus G" is attributed to the slip between the layers that constitute the liquid crystal.

\subsection{Larvicidal Activity}

The FC2B and FC3B formulations were chosen because they are structured systems, with high solubilization capacity for active substances such as $N$-tosylindole. Both samples showed biological activity against Aedes aegypti L3/L4 larvae. Table 1 shows $\mathrm{LC}_{50}$ values, where the FC2B formulation had a higher $\mathrm{LC}_{50}$ than FC3B. The control was carried out with the inert formulation and there was no biological activity against Aedes aegypti larvae. The concentration of $0.012 \mathrm{mg} / \mathrm{l}$ of temephos used by the World Health Organization (2009) is capable of causing $100 \%$ mortality of Ae. aegypti, however, the mosquito has shown resistance and toxicity in the aquatic environment. Indole derivatives are promising larvicides for the control of Aedes aegypti, at low concentrations they are effective, non-toxic (Souza et al., 2019). 
Table 1: $\mathrm{LC}_{50}$ values of the samples studied.

\begin{tabular}{cc}
\hline Samples & LC $_{\mathbf{5 0}}(\mathbf{9 5 \%} \mathbf{C I}) \mathbf{p p m}$ \\
\hline FC2A & No larvicidal activity \\
FC2B & $0.006(0.004$ to 0.065$)$ \\
FC3B & $0.100(0.008$ to 0.011$)$ \\
\hline
\end{tabular}

95\% CI: confidence interval with $95 \%$ probability.

$\mathrm{LC}_{50}$ : lethal concentration needed to kill $50 \%$ of the exposed population. ppm: parts per million.

$\mathrm{A}^{*}$ : inert formulation.

$\mathrm{B}^{*}$ : formulation with the active compound ( $N$-tosylindole).

Source: Authors (2019)

\subsection{Artemia salina Toxicity Test}

Toxicity testing using microcrustaceans is an effective method to assess the environmental toxicity of pesticides and chemicals (Minguez et al., 2016; Nunes et al., 2018; Santos et al., 2020). No indication of toxicity of the isolated components and of the formulation was found up to $1000 \mathrm{ppm}$, demonstrating to be an environmentally safe and effective larvicide for not showing toxicity in Artemia sp.

Santos et al. (2018) performed toxicity tests with pyriproxyfen at various concentrations using Daphnia magna and Artemia salina as non-target organisms to assess ecotoxicological parameters. This study demonstrated toxicological effects of pyriproxyfen on both microcrustaceans. Bussmann et al. defined the concentration range for evaluating the toxicity of compounds to non-target organisms. Very toxic compounds shows LC $_{50}$ values below 249 ppm, while compounds with intermediate toxicity exhibit $\mathrm{LC}_{50}$ ranging between 250 and 499 ppm and low toxicity molecules shows lethal concentration between 500 and $1000 \mathrm{ppm}$. The absence of system toxicity demonstrates that the developed product is not harmful to this species.

\section{Conclusion}

From the results obtained, it is possible to conclude that the formulation showed potential use and that it can be considered an important larvicidal alternative in the control of Aedes aegypti larvae, with bioactive, biodegradable and nontoxic components, showing no indication of toxicity of the isolated components and of the formulation in the toxicity tests on Artemia sp.

The system is in the form of a gel-fluid, transparent and with ideal conditions for focal application in water reservoirs, enhancing the effect of $N$-tosylindole.

\section{References}

Abramowitz, M., \& Davidson, M. W. (2012). Immersion media. Olympus Microscopy Resource Center.

Alvarez Costa, A., Gonzalez, P. V., Harburguer, L. V., \& Masuh, H. M. (2018). Effects of temephos, permethrin, and Eucalyptus nitens essential oil on survival and swimming behavior of Aedes aegypti and Anopheles pseudopunctipennis (Diptera: Culicidae) larvae. Journal of medical entomology, 55(5), 1098-1104.

Bussmann, R. W., Malca, G., Glenn, A., Sharon, D., Nilsen, B., Parris, B., ... \& Townesmith, A. (2011). Toxicity of medicinal plants used in traditional medicine in Northern Peru. Journal of ethnopharmacology, 137(1), 121-140.

Carvalho, F. C., Campos, M. L., Peccinini, R. G., \& Gremião, M. P. D. (2013). Nasal administration of liquid crystal precursor mucoadhesive vehicle as an alternative antiretroviral therapy. European Journal of Pharmaceutics and Biopharmaceutics, 84(1), $219-227$.

Corte, R. L., Melo, V. A. D., Dolabella, S. S., \& Marteis, L. S. (2018). Variation in temephos resistance in field populations of Aedes aegypti (Diptera: Culicidae) in the State of Sergipe, Northeast Brazil. Revista da Sociedade Brasileira de Medicina Tropical, 51, $284-290$.

Damasceno, B. P. G. L., Silva, J. A., Oliveira, E. E., Silveira, W., Araújo, I. B., Oliveira, A. G. D., \& Egito, E. (2011). Microemulsão: um promissor carreador para moléculas insolúveis. Revista de Ciências Farmacêuticas Básica e Aplicada, 9-18. 
Aguiar, I., dos Santos, E. R., Mafud, A. C., Annies, V., Navarro-Silva, M. A., dos Santos Malta, V. R., ... \& Carlos, R. M. (2017). Synthesis and characterization of Mn (I) complexes and their larvicidal activity against Aedes aegypti, vector of dengue fever. Inorganic Chemistry Communications, 84, 4955 .

Castro Santana, R., Fasolin, L. H., \& da Cunha, R. L. (2012). Effects of a cosurfactant on the shear-dependent structures of systems composed of biocompatible ingredients. Colloids and Surfaces A: Physicochemical and Engineering Aspects, 398, 54-63.

Santana, J. F. C. L., Ronn, A. P., Bezerra, G. N., \& da Silva Fernandes, T. L. (2021). Agravos clínicos decorrentes das arboviroses: uma revisão de literatura. Research, Society and Development, 10(2), e46010212057-e46010212057.

Souza, M. A., da Silva, L., Dos Santos, M. A., Macêdo, M. J., Lacerda-Neto, L. J., Coutinho, H. D., ... \& Cunha, F. A. (2020). Larvicidal Activity of Essential Oils Against Aedes aegypti (Diptera: Culicidae). Current Pharmaceutical Design, 26(33), 4092-4111.

Ferreira, S. G., Conceição, V. S., Gouveia, N. S., Santos, G. S., Santos, R. L. C., Lira, A. A. M., ... \& Nunes, R. S. (2015). An environmentally safe larvicide against Aedes aegypti based on in situ gelling nanostructured surfactant systems containing an essential oil. Journal of colloid and interface science, 456, 190196.

Finney, D. J. (1952). Probit analysis: a statistical treatment of the sigmoid response curve. Cambridge university press, Cambridge.

Fonseca, E. O. L., Macoris, M. D. L. D. G., Santos, R. F. D., Morato, D. G., Isabel, M. D. S. S., Cerqueira, N. A., \& Monte-Alegre, A. F. (2019). Experimental study on the action of larvicides in Aedes aegypti populations collected in the Brazilian municipality of Itabuna, Bahia, under simulated field conditions. Epidemiologia e Serviços de Saúde, 28.

Froelich, A., Osmałek, T., Snela, A., Kunstman, P., Jadach, B., Olejniczak, M., ... \& Białas, W. (2017). Novel microemulsion-based gels for topical delivery of indomethacin: Formulation, physicochemical properties and in vitro drug release studies. Journal of colloid and interface science, 507, $323-336$.

Fujiwara, G. M., Annies, V., de Oliveira, C. F., Lara, R. A., Gabriel, M. M., Betim, F. C., ... \& Zanin, S. M. (2017). Evaluation of larvicidal activity and ecotoxicity of linalool, methyl cinnamate and methyl cinnamate/linalool in combination against Aedes aegypti. Ecotoxicology and environmental safety, 139, $238-244$.

Galindo-Alvarez, J., Le, K. A., Sadtler, V., Marchal, P., Perrin, P., Tribet, C., ... \& Durand, A. (2011). Enhanced stability of nanoemulsions using mixtures of non-ionic surfactant and amphiphilic polyelectrolyte. Colloids and Surfaces A: Physicochemical and Engineering Aspects, 389(1-3), 237-245.

Grządka, E., \& Matusiak, J. (2017). The effect of ionic and non-ionic surfactants and pH on the stability, adsorption and electrokinetic properties of the alginic acid/alumina system. Carbohydrate polymers, 175, 192-198.

Ho, H. O., Hsiao, C. C., \& Sheu, M. T. (1996). Preparation of microemulsions using polyglycerol fatty acid esters as surfactant for the delivery of protein drugs. Journal of pharmaceutical sciences, 85(2), 138-143.

Huang, J., Li, J., Feng, Y., Li, K., Yan, H., Gao, P., ... \& Wang, C. (2015). Aggregation behavior of derivatives of sodium alginate and N-octyl- $\beta$-dglucopyranoside in aqueous solutions. Colloids and Surfaces A: Physicochemical and Engineering Aspects, 479, 11-17.

Hyde, S. T. (2001). Identification of lyotropic liquid crystalline mesophases. Handbook of applied surface and colloid chemistry, 2, 299-332.

Ling, Wei, L., Wang, Z., Liu, X., Guo, F., \& Fan, J. (2014). Rheological properties of lamellar liquid crystals formed in Brij97/castor oil/water systems in the presence of soybean lecithin.

Maia, J. D., La Corte, R., Martinez, J., Ubbink, J., \& Prata, A. S. (2019). Improved activity of thyme essential oil (Thymus vulgaris) against Aedes aegypti larvae using a biodegradable controlled release system. Industrial crops and products, 136, 110-120.

Martins, T. G. T., Rosa, P. V. S., Arruda, M. O., Dias, A. A. S., de Araújo Neto, A. P., Carvalho, A. M. A. S., ... \& Everton, G. O. (2021). Larvicidal activity of microparticles of Melissa officinalis L. essential oil (Lamiaceae) against Aedes aegypti (Diptera, Culicidae). Research, Society and Development, 10(1), e35710111166-e35710111166.

Meyer, B. N., Ferrigni, N. R., Putnam, J. E., Jacobsen, L. B., Nichols, D. E. J., \& McLaughlin, J. L. (1982). Brine shrimp: a convenient general bioassay for active plant constituents. Planta medica, 45(05), 31-34.

Minguez, L., Pedelucq, J., Farcy, E., Ballandonne, C., Budzinski, H., \& Halm-Lemeille, M. P. (2016). Toxicities of 48 pharmaceuticals and their freshwater and marine environmental assessment in northwestern France. Environmental Science and Pollution Research, $23(6), 4992-5001$.

Nunes, R. K., Martins, U. N., Brito, T. B., Nepel, A., Costa, E. V., Barison, A., ... \& Cavalcanti, S. C. (2018). Evaluation of (-)-borneol derivatives against the Zika vector, Aedes aegypti and a non-target species, Artemia sp. Environmental Science and Pollution Research, 25(31), 31165-31174.

Nunes, R. K., Martins, U. N., Brito, T. B., Nepel, A., Costa, E. V., Barison, A., ... \& Cavalcanti, S. C. (2018). Evaluation of (-)-borneol derivatives against the Zika vector, Aedes aegypti and a non-target species, Artemia sp. Environmental Science and Pollution Research, 25(31), 31165-31174.

Polizelli, M. A., Telis, V. R. N., Amaral, L. Q., \& Feitosa, E. (2006). Formation and characterization of soy bean oil/surfactant/water microemulsions. Colloids and Surfaces A: Physicochemical and Engineering Aspects, 281(1-3), 230-236.

Riccardi, E., \& Tichelkamp, T. (2019). Calcium ion effects on the water/oil interface in the presence of anionic surfactants. Colloids and Surfaces A: Physicochemical and Engineering Aspects, 573, 246-254.

Rosen, M. J., \& Kunjappu, J. T. (2012). Surfactants and interfacial phenomena. John Wiley \& Sons. 
Research, Society and Development, v. 11, n. 3, e3611326115, 2022

(CC BY 4.0) | ISSN 2525-3409 | DOI: http://dx.doi.org/10.33448/rsd-v11i3.26115

Salvia-Trujillo, L., Soliva-Fortuny, R., Rojas-Graü, M. A., McClements, D. J., \& Martín-Belloso, O. (2017). Edible nanoemulsions as carriers of active ingredients: A review. Annual review of food science and technology, 8, 439-466.

Santos, A. J., Pina, L. T., Galvão, J. G., Trindade, G. G., Nunes, R. K., Santos, J. S., ... \& Nunes, R. S. (2020). Clay/PVP nanocomposites enriched with Syzygium aromaticum essential oil as a safe formulation against Aedes aegypti larvae. Applied Clay Science, 185, 105394.

Santos, V. S. V., \& Pereira, B. B. (2020). Low toxicity and high efficacy in use of novel approaches to control Aedes aegypti. Journal of Toxicology and Environmental Health, Part B, 23(6), 243-254.

Sousa, J. R., Silva, F. A., Targanski, S. K., Fazolo, B. R., Souza, J. M., Campos, M. G., ... \& Soares, M. A. (2019). Synthesis and larvicidal activity of indole derivatives against Aedes aegypti (Diptera: Culicidae). Journal of Applied Entomology, 143(10), 1172-1181.

Vogel, T. J. (2011). Dynamic Behavior of Self-Assembled Langmuir Films Composed of Soluble Surfactants and Insoluble Amphiphiles (Doctoral dissertation, The Ohio State University)

World Health Organization, Special Programme for Research, Training in Tropical Diseases, World Health Organization (2009). Department of Control of Neglected Tropical Diseases, World Health Organization. Epidemic, \& Pandemic Alert. Dengue: guidelines for diagnosis, treatment, prevention and control. World Health Organization.

Yariv, D., Efrat, R., Libster, D., Aserin, A., \& Garti, N. (2010). In vitro permeation of diclofenac salts from lyotropic liquid crystalline systems. Colloids and Surfaces B: Biointerfaces, 78(2), 185-192.

Zara, A. L. D. S. A., Santos, S. M. D., Fernandes-Oliveira, E. S., Carvalho, R. G., \& Coelho, G. E. (2016). Estratégias de controle do Aedes aegypti: uma revisão. Epidemiologia e Serviços de Saúde, 25, 391-404.

Zhang, H., \& Wang, Z. (2019). Phase transition and release kinetics of polyphenols encapsulated lyotropic liquid crystals. International journal of pharmaceutics, 565, 283-293. 